\title{
Review of space charge measurement by pulsed electro-acoustic technique
}

\author{
Mohd Haris Asyraf Shee Kandar ${ }^{1}$, Nor Akmal Mohd Jamail², Nordiana Azlin Othman ${ }^{3}$, \\ Qamarul Ezani Kamarudin ${ }^{4}$, Nor Shahida Mohd Jamail ${ }^{5}$, Susama Bagchi ${ }^{6}$ \\ ${ }^{1,2,3,6}$ Faculty of Electrical and Electronic Engineering, Universiti Tun Hussein Onn Malaysia (UTHM), Malaysia \\ ${ }^{4}$ Faculty of Mechanical and Manufacturing Engineering, Universiti Tun Hussein Onn Malaysia (UTHM), Malaysia \\ ${ }^{5}$ Prince Sultan University, Saudi Arabia
}

\begin{abstract}
Article Info
Article history:

Received Feb 15, 2020

Revised Apr 15, 2020

Accepted Apr 30, 2020

\section{Keywords:}

Breakdown

Electric field

Insulation

PEA

Space charge

ABSTRACT

Pulsed electro-acoustic (PEA) is well known as a non-destructive technique for testing and describing space charge profiles in the insulation. Degradation due to moisture, ageing, external flashover, partial discharge and space charge are considered as insulation defects that is an issue in high voltage insulator. Space charge may distort the internal electric field that may lead to an electrical breakdown. For instance, a method based on an acoustic phenomenon can be used to describe the space charge profiles. This paper compares several earlier researches on different specimen of PEA method and reviews their results to find the space charge distribution profiles. The scope of the review includes types of methods used. The acoustic technique is considered for this study. It has been observed that the PEA technique successfully gives the same result as theoretical that is based on the obtained profile. Linear low-density polyethylene (LLDPE) composite demonstrates about $89 \%$ lower charge density value compared to cross-linked polyethylene (XLPE) and polypropylene (PP) composite. While the electric field value of ethylene-vinyl acetate (EVA) sample is $75 \%$ lower than low-density polyethylene (LDPE) sample. This study found that the time interval, specimen thickness and the electric field sway the space charge profiles.
\end{abstract}

Copyright $($ C 2020 Institute of Advanced Engineering and Science. All rights reserved.

\section{Corresponding Author:}

Nor Akmal Mohd Jamail,

Faculty of Electrical and Electronic Engineering,

Universiti Tun Hussein Onn Malaysia (UTHM),

86400 Batu Pahat, Johor, Malaysia.

Email:norakmal@uthm.edu.my

\section{INTRODUCTION}

Space charge accumulation or distribution in some polymer dielectric material had been extensively observed during the use of PEA method [1]. Initially, the researchers first developed this method in Japan and then, they were established in Europe. Researchers around the world showed a huge interest in space charge. Furthermore, the PEA [2,3] techniques are known as common methods for exploring space charge. Space charge accumulation inside a high voltage direct current (HVDC) causes degradation and life reduction of a dielectric material. Besides, the electric field and temperature depend on space charge, electrical conductivity and permittivity of insulation material. In the insulation system, HVDC such as cross-linked polyethylene (XLPE) generates heat when there is a flow of leakage current in the inner conductor [4]. Moreover, the geometric field known as a constant electric field, is excited by an applied voltage that is superimposed with an electric field and accumulates space charge in the insulation system. Also, the morphologies of crystalline and amorphous regions relate to space charge behaviur [5]. Undoubtedly, various issues such as the type of electrode, applied field and temperature may affect the space charge accumulation in polymers [6]. In a like manner, researcher also explored [7] the space charge in different works such as measurement of the breakdown voltage using the PEA technique. So, method that based on PEA technique [1-7] was used to measure, describe and testing space charge profiles. 
Further, there are several review papers concentrating on an acoustic over a decade. These review papers are described in Table 1 with the most imperative journals comparing the techniques. The resulting acronyms are reported in the same table which is Table 1: Measurements, Methods Used and Implementations. Based on the Table 1, all previous researchers used PEA method (experimental) to determine space charge and only researchers $[4,8]$ were used PEA method and numerical simulation to determine space charge profile. In addition, there are also some researchers that studied the electric field as a measurement. This is because the space charge values change the value of the electric field. Beside the space charge and electric field measurement, researchers also reviewed other measurement such as electrical and mechanical measurements. Here, it can see that change in space charge and electric field will affect the electrical and mechanical measurement. So, the outcome of this table clearly reveals that the measurements, used methods and implementations are related to each other. In short, not all the researchers used both the implementations at the same time. This paper is organized in a way to give general introduction on space charge, discuss about PEA theory and its concept. Altogether, PEA measurement technique, measurement results and analysis in terms of obtained profile have been discussed with an overall conclusion of the review.

Table 1. Review on space charge and several articles display a contrast between methods

\begin{tabular}{lccccccc}
\hline \multicolumn{1}{c}{ Refs. } & \multicolumn{3}{c}{ Measurements } & \multicolumn{3}{c}{ Methods Used } & \multicolumn{3}{c}{ Implementations } \\
& 1 & 2 & 3 & PEA & NS & EX & SW \\
\hline$[4]$. & $\checkmark$ & $X$ & $\checkmark$ & $\checkmark$ & $\checkmark$ & $X$ & $\checkmark$ \\
{$[8]$.} & $\checkmark$ & $X$ & $X$ & $\checkmark$ & $\checkmark$ & $X$ & $\checkmark$ \\
{$[5,7,9-20]$.} & $\checkmark$ & $X$ & $\checkmark$ & $\checkmark$ & $X$ & $\checkmark$ & $X$ \\
{$[3,21-29]$.} & $\checkmark$ & $X$ & $X$ & $\checkmark$ & $X$ & $\checkmark$ & $X$ \\
{$[6,30]$.} & $\checkmark$ & $\checkmark$ & $X$ & $\checkmark$ & $X$ & $\checkmark$ & $X$ \\
{$[31-38]$.} & $\checkmark$ & $\checkmark$ & $\checkmark$ & $\checkmark$ & $X$ & $\checkmark$ & $X$ \\
\hline
\end{tabular}

Note: 1: Space Charge, 2: Electric Field, 3: Others, PEA: Pulse Electro-Acoustic NS: Numerical Simulation, EX: Experiment, SW: Software.

\section{FUNDAMENTAL OF SPACE CHARGE}

\subsection{PEA theory, profile and concept}

PEA methods are well known as non-destructive techniques for describing space charge profiles. These techniques are an extension of previous work [39-41]. First T.Takada proposed a pulsed electroacoustic method in 1985 [2, 3]. Equally important these techniques are widely used in the field of space charge measurement [42] under the DC or AC fields. Figure 1 shows the sample of polystyrene sheet that did not contain any internal charge. When there is no internal charge in the sample, there will be no existence of space charge too in the sample. It just only the induced charge that is generated on the electrode reported by Du, Xu and Li [5], Chahal and Reddy [6] and Wei et al [7]. Figure 1 shows an example of profile obtained by PEA where red, blue and green line represent the charge density, electric field and potential [43] respectively. When DC bias voltage was injected, these three profiles were obtained.

By examining the PEA profile, parameters such as charge density, electric field and potential can be estimated. Based on the figure, the electric field was obtained by integrating charge density while electric potential was obtained by integrating electric field. Meanwhile, the resolution of the measurement system was obtained from the width of the peak and valley. The induced surface charges on the electrode actually represent the peak and the valley. To have a high resolution, the width between peak and valley should be narrower. Figure 1 illustrates that there is no peak or valley between them since the sample did not have any space charge.

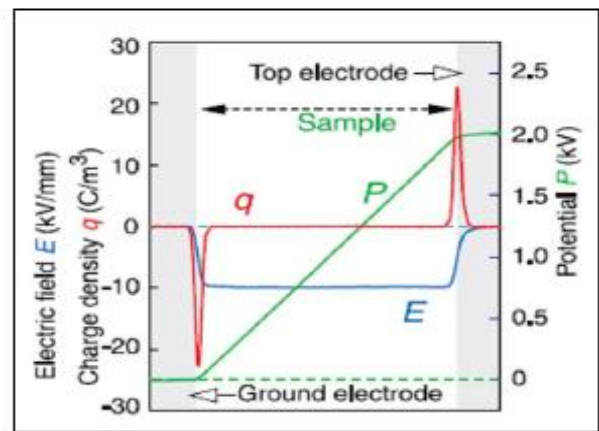

Figure 1. Example of profile obtained by PEA [5-7, 43, 44] 


\section{RESEARCH METHOD (PEA AND PWP MEASUREMENT TECHNIQUES)}

\subsection{Basic principle of the PEA method [45-47]}

Takada et al [43] presented the measurement system for PEA space charge. Space charge measurements are carried out not only in coaxial cables but also in sheet samples. Figure 2 shows the PEA space charge measurement system with the frequency $(0.001$ to $0.1 \mathrm{~Hz})$ to power frequency (typically $50 \mathrm{~Hz})$. Based on the figure below, the sample thickness is $d$ and the space charge distribution is $\mathrm{p}(\mathrm{z})$. To induce a perturbation force on each charge, pulsed electric field ep(t) is applied. The charge moves slightly due to extorted force and this movement unveils the acoustic wave that is proportional to charge distribution. An acoustic wave can be detected by piezoelectric transducer towards convert an acoustic wave to an electric signal.

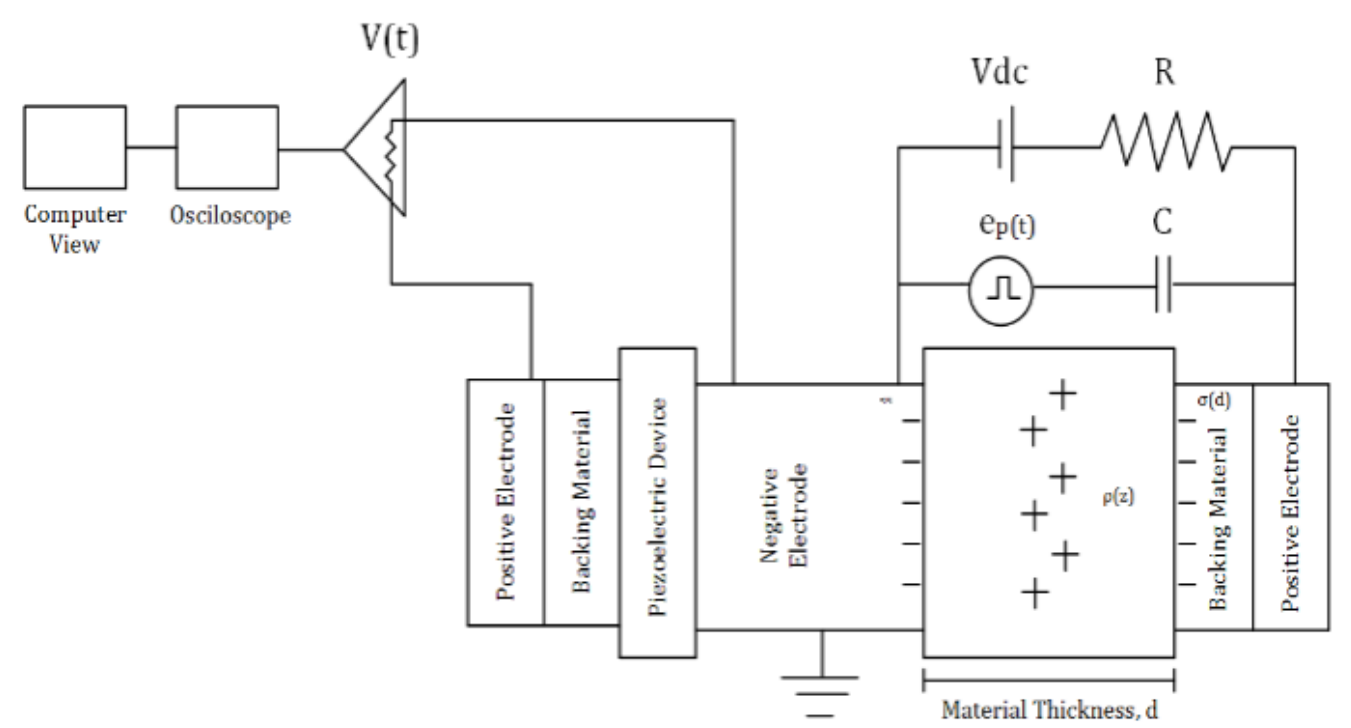

Figure 2. PEA space charge measurement system [43-45]

\subsection{Basic set-up of the PEA method}

To quote another example, Piah [44] performed an experiment with an elementary setup of the PEA method that was adopted from [46] as shown in Figure 3. Beside the dielectric sample, the parts of the system usually consist of high voltage, electrode, amplifier, absorber, and a piezoelectric device. Based on this setup, several measurement setups $[9,10]$ were applied in the systems to fulfil the requirement by doing some modifications. DC power source and pulse generator were mounted up across two electrodes in parallel and considered as a high voltage part in that system. A protecting resistor was connected in series to DC supply that acted as a current limiter in case of breakdown. Lastly, the ripple voltage was reduced by connecting coupling capacitor with a pulse generator in series.

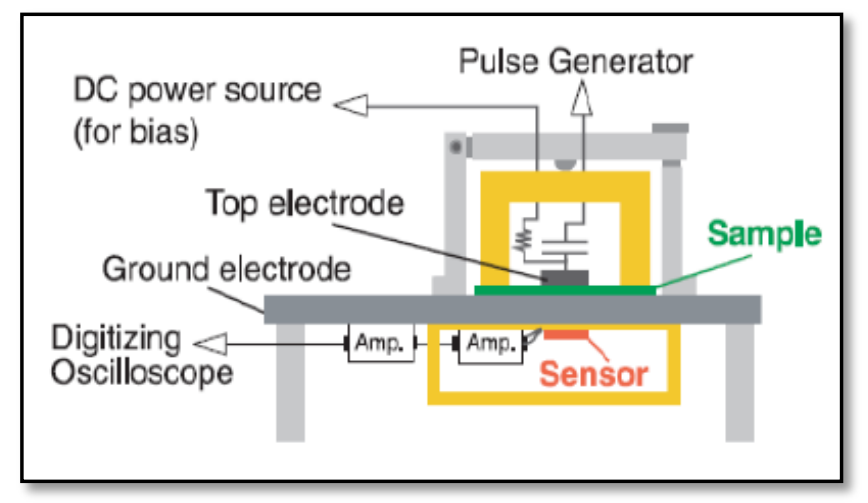

Figure 3. Basic set-up of the PEA method [6, 7] 


\subsection{Basic set-up of the PWP method}

Figure 4 shows another technique to measure space charge profile by applying principle of pressure wave propagation (PWP) method. PWP space charge measurement system is almost same as the PEA space charge measurement system. In addition, the charge probe in PWP method acts as an acoustic wave because the charge moves and spreads over it. The electrode changes due to the movement of these surface charges. The charge distribution inside the specimen specifies the time signal of displacement current. It means that the charge distribution can be obtained by determining the displacement current between the electrodes.

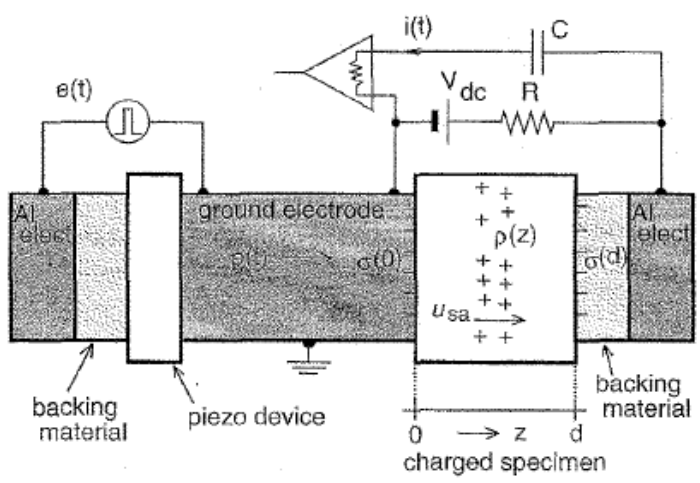

Figure 4. Basic set-up of the PWP method [6-7]

\section{MEASUREMENT RESULTS AND ANALYSIS}

\subsection{Basic set-up of the PEA method}

For a clear explanation, to obtain the space charge distribution, Poly MethylMethacrylate (PMMA) (thickness of sample $100 \mu \mathrm{m}$ to $20 \mathrm{~mm})$ sample was irradiated by an electron beam $(200 \mathrm{keV}$ and $1.0 \mathrm{nA} / \mathrm{cm} 2$ for 3 hours) as was applied in [43] using PEA method shown in Figure 5. The occurrence (due to induced surface charges) of space charge distribution can be seen between two peaks and existing valley in the sample. The shape or waveform of electric and potential were also changed respectively. The inverse triangle shape (that is found because irradiated electron was concentrated there and maximum irradiated $\sim 400 \mu \mathrm{m}$ ) represents the potential distribution in the sample. Here, the value of the electric field and the peak of the inverse triangle for electric potential placed in the same position was zero. Electric field was vanished at $\mathrm{z}=190 \mu \mathrm{m}$. Based on theoretical, the electric field should approach zero when $\mathrm{z}$ is bigger than the thickness of the sample.

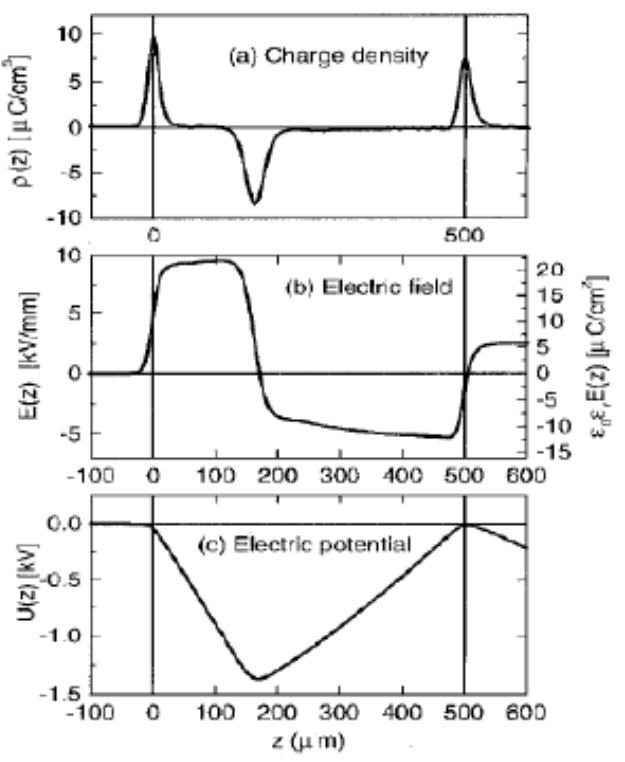

Figure 5. Experimental results of poly methyl methacrylate (PMMA) sample containing space charge [43] 


\subsection{Characteristic of the PEA}

The result for characteristic of the PMMA sample based on the experiment was extracted from the measured space charge data as reported in the published papers by the researchers [35, 43] using PEA method and they are shown in Table 2. According to the thickness and relative resolution of the samples, the mostly used thickness and relative resolution are $100 \mu \mathrm{m}$ to $20 \mathrm{~mm}$ and $2 \%$ to $5 \%$.

Table 2. Characteristic of the PEA method [35, 43]

\begin{tabular}{ll}
\hline \multicolumn{1}{c}{ Characteristic } & \multicolumn{1}{c}{ PEA Method } \\
\hline Excitation method & Electric pulse \\
Thickness (samples) & $100 \mu \mathrm{m}$ to $20 \mathrm{~mm}$ \\
Relative resolution & $2 \%$ to $5 \%$ \\
Minimum space resolution & $\sim 5 \mu \mathrm{m}$ \\
Noise and electric shielding & $\mathrm{HV}$ and signal circuits completely separated. Can \\
& be used when corona discharge occurs \\
$\begin{array}{l}\text { Very quick varying space charge distribution } \\
\text { measurement }\end{array}$ & Possible \\
\hline
\end{tabular}

\subsection{Charge density results}

The analysis of charge density measurement for composites were done based on the published results by the researchers $[3,6,7,11]$. Figure 6 shows the charge density results where red, green and blue, and orange line represents cross-linked polyethylene (XLPE), low density polyethylene (LLDPE) and polypropylene (PP) with different specimen thickness respectively. Both measurements were performed by PEA method.

It is observed that the higher the magnitude of electric field stress tends to increase the magnitude of the space charge [48-50]. At the same time, apply of higher electric field stress generated a higher formation rate of space charge. In the same way, under the same electric field stress an increased charging time increased the magnitude of space charge. These results show that the amplitudes of charge density can be estimated by referring the electric field stress and charging time. Undoubtedly, the blue line represents LLDPE composite contributes the best condition of space charge profile due to its low charge density value which is $\pm 20 \mathrm{C} / \mathrm{m}^{3}$ compared to XLPE and PP composite.

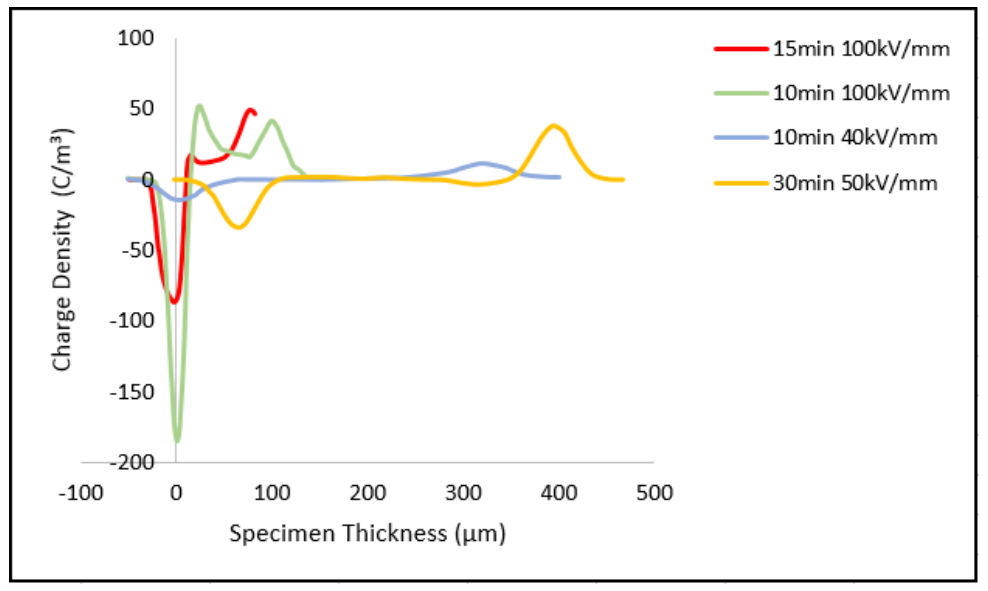

Figure 6. Space charge distribution of composite at different electric fields of 40kV/mm, 50kV/mm and $100 \mathrm{kV} / \mathrm{mm}[3,6,7,11]$

\subsection{Electric field results}

The electric field results were done by researchers $[6,10]$. Purple and black line indicate low density polyethylene (LDPE) and ethylene-vinyl acetate copolymer (EVA) sample, respectively. The specimen thickness for LDPE composite was $200 \mu \mathrm{m}$ while the specimen thickness for EVA composite was $600 \mu \mathrm{m}$. Based on their paper [6], the measurement was performed on two different types (only time interval was different between each type). It means that a $100 \mathrm{kV} / \mathrm{mm}$ DC field were subjected to LDPE sample and only time interval was different. Purple line graph in Figure 7 represents the result of LDPE sample with 10 minutes time interval and $100 \mathrm{kV} / \mathrm{mm}$ DC field. 
Compared to EVA sample which is represented by a black line, the time interval is quite long, i.e. 30 minutes while the DC field was subjected to $-25 \mathrm{kV} / \mathrm{mm}$. As expected, the $100 \mathrm{kV} / \mathrm{mm}$ DC field that was subjected can be justified to contain a higher space charge. Based on theoretical, the space charge value shall increase linearly with the electric field value. Instead, the electric field value of EVA sample was $75 \%$ lower than LDPE sample. Therefore, it can be concluded that the electric field in LDPE sample was distorted seriously by space charge accumulation compared to the EVA sample in term of time interval and specimen thickness.

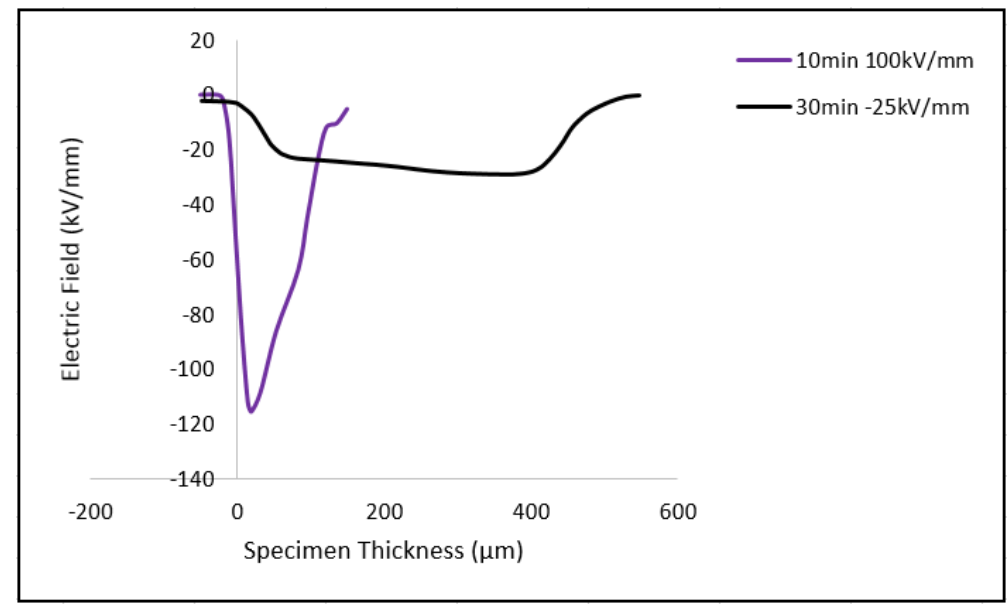

Figure 7. Electric field distribution in LDPE and EVA composite taken after 10min and 30min after applied field of $100 \mathrm{kV} / \mathrm{mm}$ and $-25 \mathrm{kV} / \mathrm{mm}[6,10]$

\section{CONCLUSION}

In a nutshell, by using this method (PEA measurement) it can enable the prediction about the lifetime of the insulation. Moreover, it should find applicable expansion in research fields and PEA method was significantly improved nowadays with the increasing of industrial application compared to the initially presented method three decades ago. To sum up, the PEA method can be highlighted as a convenient way to describe the space charge profile.

Another essential point, LLDPE composite revealed a superlative condition of the space charge profile which is $\pm 20 \mathrm{C} / \mathrm{m}^{3}$ compared to XLPE and PP composite due to its low charge density. While, the value of space charge distribution affects the value of electric field where the value of space charge is directly proportional to the value of the electric field and the electric field value in EVA sample is $75 \%$ lower than LDPE sample.

\section{ACKNOWLEDGEMENTS}

The authors gratefully acknowledge the Research Management Centre of University Tun Hussein Onn Malaysia under grant GPPS Vot U953, Ministry of Education Malaysia for supporting this research under Fundamental Research Grant Scheme for Research Acculturation of Early Career Researchers (FRGSRACER) Vot No. RACER/1/2019/TK04/UTHM//6, partially sponsored by Universiti Tun Hussein Onn Malaysia and Kvolt Focus Group Team.

\section{REFERENCES}

[1] M. Fukuma, T. Maeno, K. Fukunaga, and M. Nagao, "High repetition rate PEA system for in-situ space charge measurement during breakdown tests," IEEE Trans. Dielectr. Electr. Insul., vol. 11, no. 1, pp. 155-159, 2004.

[2] F. Tian and C. Hou, "A trap regulated space charge suppression model for LDPE based nanocomposites by simulation and experiment," IEEE Trans. Dielectr. Electr. Insul., vol. 25, no. 6, pp. 2169-2177, 2018.

[3] N. Ruangkajonmathee, R. Thiamsri, and B. Marungsri, "Space Charge Distribution in 22 kV XLPE Insulated Cable by using Pulse Electroacoustic Measurement Technique," International Journal of Electrical and Computer Engineering, vol. 6, no. 12, pp. 1494-1497, 2012.

[4] C. Jörgens and M. Clemens, "Breakdown voltage of high voltage direct current cable insulations considering space charges," 2017 18th International Symposium on Electromagnetic Fields in Mechatronics, Electrical and Electronic Engineering (ISEF) Book of Abstracts, pp. 1-3, 2017. 
[5] B. X. Du, H. Xu, and J. Li, "Effects of mechanical stretching on space charge behaviors of PP/POE blend for HVDC cables," IEEE Trans. Dielectr. Electr. Insul., vol. 24, no. 3, pp. 1438-1445, 2017.

[6] J. S. Chahal and C. C. Reddy, "Dependence of space charge dynamics in LDPE on history of voltage application," IEEE Trans. Dielectr. Electr. Insul., vol. 23, no. 2, pp. 683-691, 2016.

[7] Y. Wei, H. Mu, J. Deng, and G. Zhang, "Effect of Space Charge on Breakdown Characteristics of Aged Oil-paper Insulation under DC Voltage," IEEE Trans. Dielectr. Electr. Insul., vol. 23, no. 5, pp. 3143-3150, 2016.

[8] Z. Lv, S. M. Rowland, and K. Wu, "A model and simulation of fast space charge pulses in polymers," J. Phys. D. Appl. Phys., vol. 50, no. 44, pp. 1-10, 2017.

[9] M. C. Lanca et al., "Comparative study of space charge in the polymeric insulation of power cables using PEA, isothermal and non-isothermal currents measurements," 2005 12th International Symposium on Electrets, pp. 284-287, 2005.

[10] Z. Li, W. Cao, G. Sheng, X. Jiang, and M. G. Danikas, "Experimental study on space charge and electrical strength of $\mathrm{MgO}$ nano-particles/polypropylene composite," IEEE Trans. Dielectr. Electr. Insul., vol. 23, no. 3, pp. 1812-1819, 2016.

[11] C. J. Zheng, B. Guan, H. Zhao, J. M. Yang, and Z. Sun, "Effects of surface morphology on space charge formation in low density polyethylene," IEEE Trans. Dielectr. Electr. Insul., vol. 23, no. 2, pp. 1183-1189, 2016.

[12] J. W. Zha, Y. H. Wu, S. J. Wang, D. H. Wu, H. Da Yan, and Z. M. Dang, "Improvement of space charge suppression of polypropylene for potential application in HVDC cables," IEEE Trans. Dielectr. Electr. Insul., vol. 23, no. 4, pp. 2337-2343, 2016.

[13] Y. Wang, J. Wu, and Y. Yin, "Investigation of surface trap distribution in LDPE/SiO2 nanocomposite based on simultaneous observation of space charge and relaxation current," IEEE Trans. Dielectr. Electr. Insul., vol. 23, no. 6, pp. 3486-3493, 2016.

[14] Zou, Runhao, et al, "Space charge and DC breakdown behavior of natural ester impregnated insulation paper with different ageing conditon," 2017 International Symposium on Electrical Insulating Materials (ISEIM), pp. 315-318, 2017.

[15] S. Li, N. Zhao, Y. Nie, X. Wang, G. Chen, and G. Teyssedre, "Space charge characteristics of LDPE nanocomposite/LDPE insulation system,” IEEE Trans. Dielectr. Electr. Insul., vol. 22, no. 1, pp. 92-100, 2015.

[16] Y. Wang, J. Wu, W. Li, and Y. Yin, "Space charge measurement of cross-linked polyethylene at low temperatures,” 2017 International Symposium on Electrical Insulating Materials (ISEIM), pp. 180-183, 2017.

[17] N. Liu, Z. Li, G. Chen, Q. Chen, and S. Li, "Space charge dynamics of CF4 fluorinated LDPE samples from different fluorination conditions and their DC conductivities," Mater. Res. Express, vol. 4, no. 7, 2017.

[18] G. Li, X. Zhou, Y. Wei, C. Hao, and Q. Lei, "Effect of BN nanosheet concentration on space charge characteristics in XLPE/BNNS nanocomposites," Mater. Res. Express, vol. 6, no. 11, 2019.

[19] J. W. Zhang, et al., "Space charge behavior of silicone rubber nanocomposites with thermal step method," Jpn. J. Appl. Phys., vol. 55, no. 8, 2016.

[20] D. Qiang, Y. Wang, X. Wang, G. Chen, and T. Andritsch, "The effect of filler loading ratios and moisture on DC conductivity and space charge behaviour of $\mathrm{SiO} 2$ and hBN filled epoxy nanocomposites," J. Phys. D. Appl. Phys., vol. 52, no. 39, 2019.

[21] Z. Lei, et al., "Space charge characteristics of XLPE and semiconductive layer coated with graphene," IEEE Trans. Dielectr. Electr. Insul., vol. 27, no. 1, pp. 128-131, 2020.

[22] D. Saha, A. G. Anisimov, R. M. Groves, I. A. Tsekmes, P. H. F. Morshuis, and R. Kochetov, "Epoxy-hBN nanocomposites: A study on space charge behavior and effects upon material," IEEE Trans. Dielectr. Electr. Insul., vol. 24, no. 3, pp. 1718-1725, 2017.

[23] L. Galloy, L. Berquez, F. Baudoin, and F.- Toulouse, "High-resolution pulsed electro-ACOUSTIC (HR PEA) measurement of space charge in outer space dielectric materials," IEEE Transactions on Dielectrics and Electrical Insulation, vol. 23, no. 5, pp. 3151-3155, 2016.

[24] D. He, W. Wang, J. Lu, G. Teyssedre, and C. Laurent, "Space charge characteristics of power cables under AC stress and temperature gradients," IEEE Trans. Dielectr. Electr. Insul., vol. 23, no. 4, pp. 2404-2412, 2016.

[25] T. T. N. Vu, G. Teyssedre, S. Le Roy, and C. Laurent, "Space charge criteria in the assessment of insulation materials for HVDC," IEEE Trans. Dielectr. Electr. Insul., vol. 24, no. 3, pp. 1405-1415, 2017.

[26] H. Hussaini, A. A. Adam, and A. A. Susan, "Review of Space-charge Measurement using Pulsed ElectroAcoustic Method: Advantages and Limitations," Int. J. Eng. Res. Appl., vol. 5, no. 4, pp. 90-95, 2015.

[27] G. Rizzo, P. Romano, A. Imburgia, and G. Ala, "Review of the PEA method for space charge measurements on HVDC cables and mini-cables," Energies, vol. 12, no. 18, 2019.

[28] A. Imburgia, R. Miceli, E. R. Sanseverino, P. Romano, and F. Viola, "Review of space charge measurement systems: Acoustic, thermal and optical methods," IEEE Trans. Dielectr. Electr. Insul., vol. 23, no. 5, pp. 3126-3142, 2016.

[29] S. Wang, Y. Tu, L. Fan, C. Yi, Z. Wu, and L. Li, "Space charge dynamic of irradiated cyanate ester/epoxy at cryogenic temperatures," J. Phys. D. Appl. Phys., vol. 51, no. 10, 2018.

[30] S. Wang, S. Luo, Y. Tu, C. Wang, and S. Qin, "Effect of polarity reversal on space charge properties of CB/LDPE composite under DC field," IEEE Trans. Dielectr. Electr. Insul., vol. 24, no. 3, pp. 1349-1354, 2017.

[31] B. X. Du, J. Li, and Y. Sekii, "Effects of ZnO particles on space charge of EVA copolymer for HVDC cable accessory insulation," IEEE Trans. Dielectr. Electr. Insul., vol. 24, no. 3, pp. 1503-1510, 2017.

[32] B. X. Du, Z. L. Li, and Z. R. Yang, "Field-dependent Conductivity and Space Charge Behavior of Silicone Rubber / SiC Composites," IEEE Trans. Dielectr. Electr. Insul., vol. 23, no. 5, pp. 3108-3116, 2016. 
[33] C. Zhou and G. Chen, "Space charge and AC electrical breakdown strength in polyethylene," IEEE Trans. Dielectr. Electr. Insul., vol. 24, no. 1, pp. 559-566, 2017.

[34] B. X. Du, H. Xu, J. Li, and Z. Li, "Space charge behaviors of PP/POE/ZnO nanocomposites for HVDC cables," IEEE Trans. Dielectr. Electr. Insul., vol. 23, no. 5, pp. 3165-3174, 2016.

[35] S. Agnel, "Review of space charge measurements in high voltage DC extruded cables by the thermal step method," IEEE Electrical Insulation Magazine, vol. 33, no. 4, pp. 34-41, 2017.

[36] Y. Li, M. Tian, Z. Lei, X. Xu, and S. Wang, "Effect of Silicon dioxide nano-filler on dielectric and space charge properties of epoxy resin," Gaodianya Jishu/High Volt. Eng., vol. 44, no. 6, pp. 1870-1877, 2018.

[37] T. Z. et Al., "Investigation on space charge dynamics and mechanical properties of Epoxy Alumina nanocomposites," J. Phys. D Appl. Phys., vol. 7, no.2, 2018.

[38] J. W. Zha, Q. Cheng, H. Da Yan, W. K. Li, and Z. M. Dang, "Effect of multi-structured zinc oxide on the electrical properties of polypropylene insulating materials," J. Phys. D. Appl. Phys., vol. 50, no. 30, 2017.

[39] T. Takada and T. Sakai, "Measurement of electric fields at a dielectric/electrode interface using an acoustic transducer technique," IEEE Trans. Electr. Insul., vol. EI-18, no. 6, pp. 619-628, 1983.

[40] T. Maeno, et al, "Pulsed Electro-Acoustic Method for the Measurement of Volume Charges in E-Beam Irradiated Pmma," Conference on Electrical Insulation \& Dielectric Phenomena - Annual Report 1985, pp. 389-397, 1985.

[41] T. Takada, T. Maeno, and H. Kushibe, "An electric stress-pulse technique for the measurement of charges in a plastic plate irradiated by an electron beam," IEEE Trans. Electr. Insul., vol. EI-22, no. 4, pp. 497-501, 1987.

[42] T. Maeno, "Portable space charge measurement system using the pulsed electrostatic method," IEEE Trans. Dielectr. Electr. Insul., vol. 10, no. 2, pp. 331-335, 2003.

[43] K. Fukunaga, "Innovative PEA space charge measurement systems for industrial applications," IEEE Electr. Insul. Mag., vol. 20, no. 2, pp. 18-26, 2004.

[44] M. Meziani, et al, "Effect of space charge layers on the electric field enhancement at the physical interfaces in power cable insulation," IEEE Trans. Dielectr. Electr. Insul., vol. 23, no. 6, pp. 3725-3733, 2016.

[45] T. Takada, et al, "Comparison between the PEA method and the PWP method for space charge measurement in solid dielectrics," IEEE Trans. Dielectr. Electr. Insul., vol. 5, no. 6, pp. 944-951, 1998.

[46] M. A. M. Piah, "Comparative study on space charge distribution measurements using PEA and PWP methods on high voltage insulation," Jurnal Teknologi, vol. 64, no. 4, pp. 43-47, 2013.

[47] X. Xu, et al, "Development of the Space Charge Measurement Techniques Based on Pulsed Electric-acoustic Method for HVDC Power Cables," ICHVE 2016 - 2016 IEEE Int. Conf. High Volt. Eng. Appl, pp. 1-4, 2016.

[48] M. H. M. Sharif, N. A. M. Jamail, N. A. Othman, and M. S. Kamarudin, "Analysis of electric field and current density on XLPE insulator," Int. J. Electr. Comput. Eng., vol. 7, no. 6, pp. 3095-3104, 2017.

[49] A. N. Ramani, A. M. Ariffin, G. Vijian, and A. B. A. Ghani, "The effects of nano fillers on space charge distribution in cross-linked polyethylene," Int. J. Electr. Comput. Eng., vol. 7, no. 6, pp. 3147-3152, 2017.

[50] M. H. A. S. Kandar, "Space charges analysis on XLPE insulator with effect of uniform layer contamination," TELKOMNIKA, vol. 17, no. 4, pp. 2001-2007, 2019. 